Thorax (1950), 5, 169.

\title{
UNILATERAL PARALYSIS OF THE DIAPHRAGM AND LARYNX ASSOCIATED WITH INFLAMMATORY LUNG DISEASE
}

\author{
BY \\ BERNARD FREEDMAN \\ From St. Giles' and Dulwich Hospitals, London
}

Unilateral paralysis of the diaphragm, not the result of a deliberate operative procedure, is uncommon. It may have a variety of causes, but so far as I am aware pneumonia* has never previously been included amongst them.

The commoner causes of unilateral paralysis are diseases of the cervical spinal cord affecting the anterior horn cells of the fourth segment, such as poliomyelitis, tumour, progressive muscular atrophy, myelitis, haemorrhage, and injuries and caries of the cervical vertebrae. Peripheral lesions of the phrenic nerve or its roots include neck wounds, polyneuritis (usually diphtheritic), destruction by neoplastic masses (usually near the hilum of the lung), and avulsion from birth injury as an extension of Erb's palsy, of which about 20 cases have been described. A number of cases occurring during the course of pulmonary tuberculosis have been ascribed to involvement of the phrenic nerve in scar tissue. Two instances in newborn infants, not associated with Erb's palsy, were attributed to intrauterine malposition (Blattner, 1942 ; Light, 1944). An aortic aneurysm may rarely be responsible (Sanguinetti and Galzerano, 1943). Eventration of the diaphragm, a condition in which the affected dome is much raised and thinned with fibrous replacement, may in a sense be regarded as a form of phrenic palsy. Though usually regarded as congenital, it may in some instances be the atrophic result of permanent interruption of the nerve supply.

Diseases of the diaphragm itself, acute diaphragmitis (Hedblom's syndrome), trichiniasis, and the degenerations that may result from prolonged contact with purulent effusions, severe pneumonia and asphyxial states, all of course impair diaphragmatic function, which would imply impaired descent on inspiration. Whether they would cause actual paralysis is open to question.

A search of the literature has failed to reveal any previous record of unilateral paralysis of the diaphragm due to pneumonia. Upward displacement of the diaphragm in pneumonia has been reported by Wu (1932), but such elevation is apparent only, being in fact a failure to descend during deep inspiration as much as the dome of the sound side. It is due to a loss of expansibility of the lung resulting from the consolidation, and is apparent only in radiographs taken in full inspiration. The extensive reviews by Graeser, Wu, and Robertson (1934), Davies, Hodgson, and Whitby (1935), and Heffron (1939) of the radiological findings in pneumonia likewise mention this apparent elevation during the acute phase, but

*Throughout this article the term "pneumonia" is used to cover a variety of inflammations affecting the lung.-EDIror. 
none mentions paralysis. Leitner (1938) described diaphragmatic palsy following artificial pneumothorax due to mediastinal pleurisy. His diagnosis may be questioned, as the diaphragm, though raised, was fixed.

\section{Criteria of Unilateral Diaphragmatic Paralysis}

Clinically unilateral diaphragmatic paralysis may be suspected but cannot be diagnosed with certainty. Physical signs, occasionally striking, are more often so insignificant as to be easily missed or overshadowed by coexisting processes, and when present are not usually diagnostic. The following criteria were therefore adopted in the cases described. (1) Elevation of the diaphragm 1.5 in. (about $4 \mathrm{~cm}$.) or more above the normal position: the extent of the elevation was determined by comparison with the sound side. For purposes of measurement the right dome was arbitrarily taken as being normally $\frac{1}{2}$ in. $(1.25 \mathrm{~cm}$.) higher than the left. (2) Paradoxical movement, especially noticeable on sniffing: the sound side descends on inspiration, while the paralysed side rises by a smaller amount. This phenomenon is rendered more obvious when the subject sniffs sharply. The latter test is a severe one, and may be positive with incompletely paralysed diaphragms. A positive response to the sniff test was not therefore taken by itself as the only criterion.

Direct stimulation of the phrenic nerve with simultaneous radiographic control would have been crucial, but was scarcely practicable under circumstances of acute illness.

\section{DifFERENTIAL Diagnosis}

Elevation of the diaphragm may result from its being pushed up as, for example, by a subphrenic abscess. It may also result from the diaphragm being pulled up by adhesions. In both these circumstances the diaphragm is fixed ; there is no paradoxical movement. However, an apparently paradoxical movement may occur with a fixed diaphragm, especially in breathers of the "thoracic" type. This is due to elevation of the anterior part of the thoracic cage during inspiration and with it the anterior diaphragmatic attachments. Careful inspection of films taken in both phases will demonstrate failure to rise relatively to the front of the thoracic cage. This is unlikely to cause confusion on fluoroscopy, as the elevation that occurs is slight and occurs towards the end of inspiration.

Apparent elevation may result from the inspiratory descent on the affected side being less than that on the sound side. This factor will operate in films taken in full inspiration, as is the universal routine. The phenomenon occurs reflexly in painful conditions, such as pleurisy and fibrositis of the chest-wall (pleurodynia), and in pneumonia, due to loss of expansibility in the consolidated portion as previously mentioned (Wu, 1932).

Elevation of the diaphragm may be associated with the Kienböck (1898) phenomenon.* In hydropneumothorax the fluid level may be seen to rise on inspiration. The diaphragm is masked by the fluid in the erect posture. Kienböck attributed the phenomenon to phrenic palsy, but this may be absent. In the latter event the rise in fluid level is caused by movement of the mediastinum towards the affected side.

* The term Kienböck phenomenon is often, but erroneously, used to describe the paradoxical movement of phrenic paralysis. Kienböck's description referred to the occurrence of this movement in the fluid level of hydropneumothorax. 


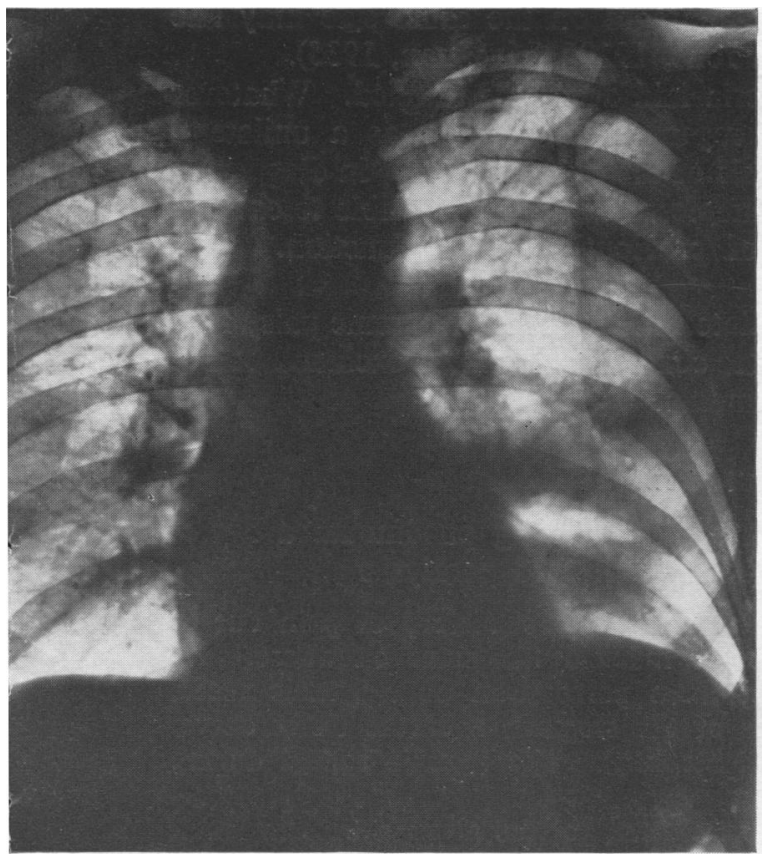

FIG. 1.

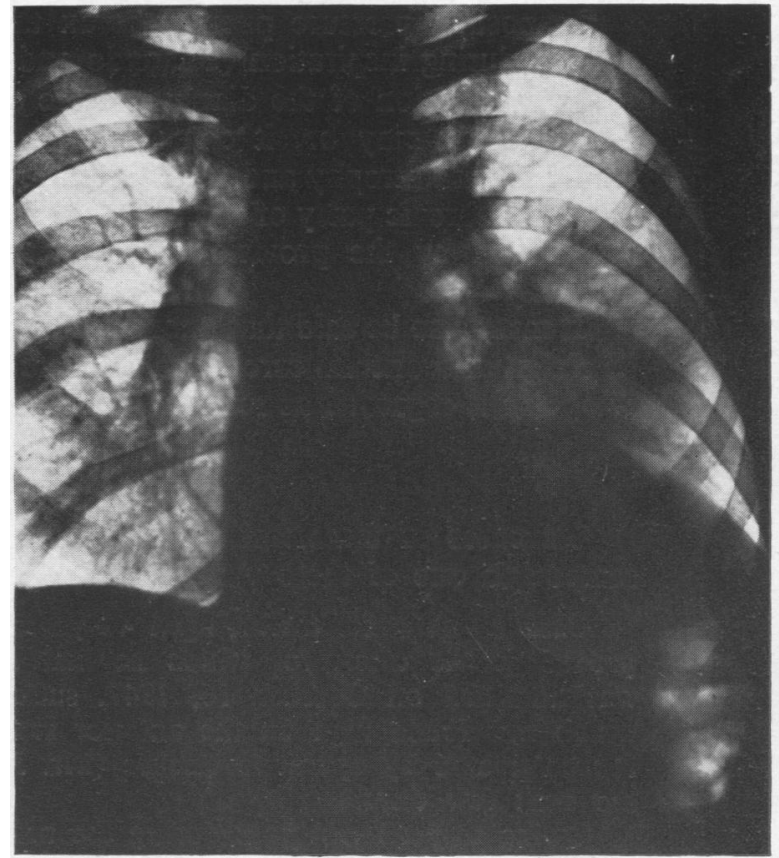

Fig. 2.

Fig. 1.-Case 1 twenty-one days after operation. Post-operative pneumonia has progressed to an abscess with fluid level in the subapical segment of the left lower lobe.

Fig. 2.-Case 1. The left dome of the diaphragm is raised 2.5 in. $(6.3 \mathrm{~cm}$.) above its normal level.

FIG. 3.-Case 1. Complete recovery of diaphragmatic mobility ; residual fibrosis.

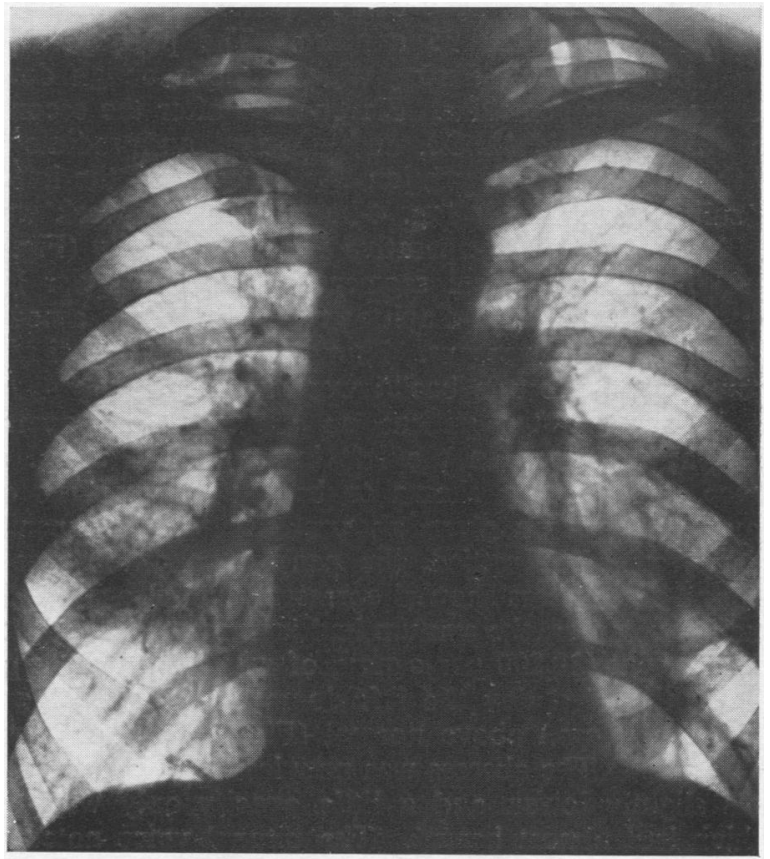

Fig. 3. 
In positive-pressure pneumothorax the diaphragm on the same side may rise slightly during inspiration (Udaondo and Vadone, 1929 ; Stivelman, 1935).

In eventration of the diaphragm the criteria laid down are fulfilled. Whatever the aetiology may be, it can therefore be regarded functionally as a unilateral paralysis with atrophy and replacement fibrosis of the muscle fibres. In diagnosing a case of phrenic palsy of recent onset it is therefore desirable if possible to exclude eventration by the provision of evidence of previously normal function. It is distinctly rare.

It must also be said that pneumonia associated with unilateral phrenic palsy may be a sign of bronchial carcinoma, and the latter condition should be excluded before the palsy is regarded as resulting from pneumonia.

\section{Case Reports}

Six cases of unilateral diaphragmatic paralysis following pneumonia are presented ; in one of these there was an ipsilateral vocal cord paralysis.

Case 1.-A street trader, aged 40 years, gave a two years' history of pain due to proved gastric ulcer, for which he had received medical treatment elsewhere. $\mathrm{He}$ was admitted on October 16, 1947, suffering from perforation of a gastric ulcer, which was found high on the anterior surface of the stomach near the lesser curve. It was treated by operative closure (Mr. J. L. Stephen). The pyrexia settled during the next few days.

Owing to persistent pain during the next five weeks, he was given a barium meal. This showed that a large gastric ulcer was still present. Partial gastrectomy was therefore performed, with drainage of a pelvic abscess that was found (Mr. J. L. Stephen), the anaesthetic being " pentothal," nitrous oxide, oxygen, and "myanesin"; the operation lasted 95 minutes. The post-operative pyrexia failed to fall during the next few days, during which time a cough developed and persisted in spite of intramuscular penicillin. Eleven days after the second operation the pyrexia increased to $101.2^{\circ} \mathrm{F}$. $\left(38.4^{\circ} \mathrm{C}\right.$.), and physical and radiological signs of bronchopneumonia with early abscess formation were present in the left lower lobe. Oral sulphadimidine ("sulphamezathine") $1 \mathrm{~g}$. 4-hourly for one week was given without effect.

On the 21st post-operative day radiography (Fig. 1) showed an abscess with fluid level in the sub-apical segment of the left lower lobe, with slight elevation of the posterior part of the diaphragm. The sputum amounted to $10 \mathrm{oz}$. $(280 \mathrm{ml}$.) daily of which one-third was pus. Numerous pneumococci and a few Staph. albus were grown from it; no tubercle bacilli were found.

I first saw the patient on the 32nd post-operative day, when, in addition to the physical signs in the left lower lobe, I noted a peculiar bitonal quality in his voice, subsequently shown to be due to paralysis of the left vocal cord. For ten days he had been given postural drainage and penicillin (500,000 units twice daily), the pyrexia had settled, the general condition was improved, and the pneumonitis around the abscess showed corresponding clearing radiologically, but the abscess cavity itself was larger, the sputum had increased to 1 pint $(560 \mathrm{ml}$.) a day, and a leucocytosis was present $(20,800$ per c.mm., of which $74 \%$ were polymorphs).

By the 43rd day the left dome of the diaphragm was considerably raised, being $2.5 \mathrm{in}$. (6.3 cm.) above normal (Fig. 2), and on fluoroscopy it exhibited paradoxical movement. The abscess was now less in evidence. By the 60th day the left diaphragm was slightly lower, and a little opacity only was present at the site of the abscess, which had almost healed. The bitonal voice noted on the 32 nd day was unchanged, 
and indirect laryngoscopy disclosed complete paralysis of the left vocal cord, which was in the cadaveric position, the right cord crossing the midline to meet it on phonation. The patient was discharged 67 days after the onset of the bronchopneumonia.

Subsequent follow-up showed on the 84th day returning though incomplete contractility of the left diaphragm, and fibrosis at the site of the abscess. The vocal cord paralysis persisted. The general condition was fairly good, only a moderate amount of mucopurulent sputum being produced. The erythrocyte sedimentation rate (E.S.R.) was $20 \mathrm{~mm}$. in one hour (Westergren). Incomplete closure of the abscess was suspected, but the patient declined bronchography to settle this point. He was therefore given inhalations of nebulized penicillin solution and more postural drainage. By the 112th day the chest radiograph (Fig. 3) was clear except for left basal fibrosis. The left vocal cord was now fixed in the midline, indicating recovery of the adductor group of muscles only, but four and a half months after operation it had returned to the cadaveric position. After 20 months the cord showed a little movement amounting to about one-fifth of normal, and was atrophied; the voice retained its peculiar timbre.

Though possibly irrelevant to the condition of his phrenic and recurrent laryngeal nerves, it must be added that the patient developed hepatitis with jaundice on March 3. Its onset was 135 days after his first operation, when he received two pints of plasma.

The course and diagnosis of this patient's illness may be summarized as perforated gastric ulcer with operative closure, and partial gastrectomy five weeks later followed by pneumonia and abscess in the sub-apical segment of the left lower lobe. Later serum hepatitis developed. There was paralysis of the left vocal cord, first noticed four weeks after the onset of pneumonia and lasting over four and a half months. Twenty months later there was a very slight recovery of movement.

Paralysis of the left dome of the diaphragm, present six weeks after the onset of pneumonia (possibly beginning at the third week) and lasting for 10 weeks, was noted.

Case 2.-A shoe repairer, aged 29 years, had an acute illness beginning with a rigor, followed shortly by stabbing pain in the right loin, worse on breathing. On the third day he coughed up a few small blood clots, and was admitted to hospital on June 14, 1947. There had been no cough or sputum. On admission his temperature was $102.6^{\circ} \mathrm{F}$. $\left(39.2^{\circ} \mathrm{C}\right.$.), pulse rate 130 , respiration rate 28 . At the base of the right lung there were impaired percussion note, diminished breath sounds, and a few crepitations. He was treated with oral sulphadimidine (sulphamezathine) $1.5 \mathrm{~g}$. 6-hourly, and intramuscular penicillin 20,000 units, increased after four days to 50,000 units, 3-hourly for a total of seven days. The patient failed to respond to this treatment, his pyrexia remaining at $101^{\circ} \mathrm{F} .\left(38.3^{\circ} \mathrm{C}\right.$.) by lysis reaching normal on the 18th day. No tubercle bacilli were found in the sputum.

On the sixth day radiography (Fig. 4) showed a small right-sided pleural effusion, opacity in the lower zone suggesting consolidation, and slight elevation of the right dome of the diaphragm. Signs of effusion increased; a specimen of the fluid was clear yellow, and contained lymphocytes and polymorphs in approximately equal numbers; no tubercle bacilli were seen in the deposit, and no organisms were grown on culture. By the 19th day the effusion was absorbing, friction being audible over the lower part of the right side of the chest, with whispering pectoriloquy, though the percussion note was still very dull. Although the temperature had reached normal, the pulse rate was 120 , and the E.S.R. $53 \mathrm{~mm}$. in one hour (Wintrobe). On the 28th day radiography (Fig. 5) showed clearing of the effusion and of the lung fields but for a very little opacity at the right base and a thickened fissure; the right dome of the diaphragm was further elevated, being 2.1 in. $(5.3 \mathrm{~cm}$.) above normal, and the costo-phrenic angle was obliterated. Gastric lavage, in the absence of sputum, 


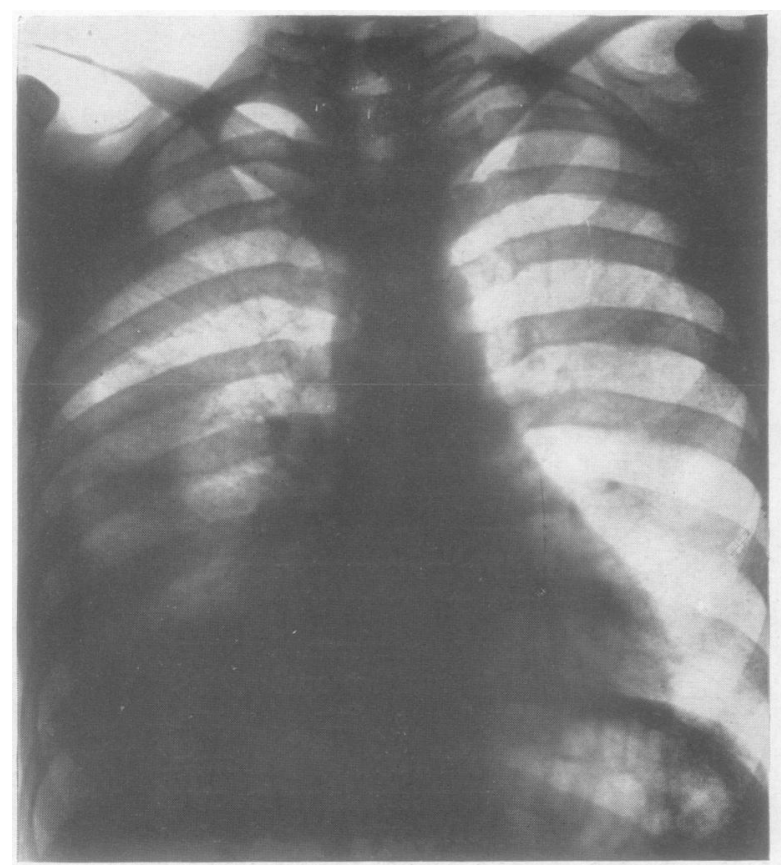

FIG. 4.-Case 2 sixth day of illness; a small effusion is present in the right pleural cavity, and pneumonic opacity is present centrally.

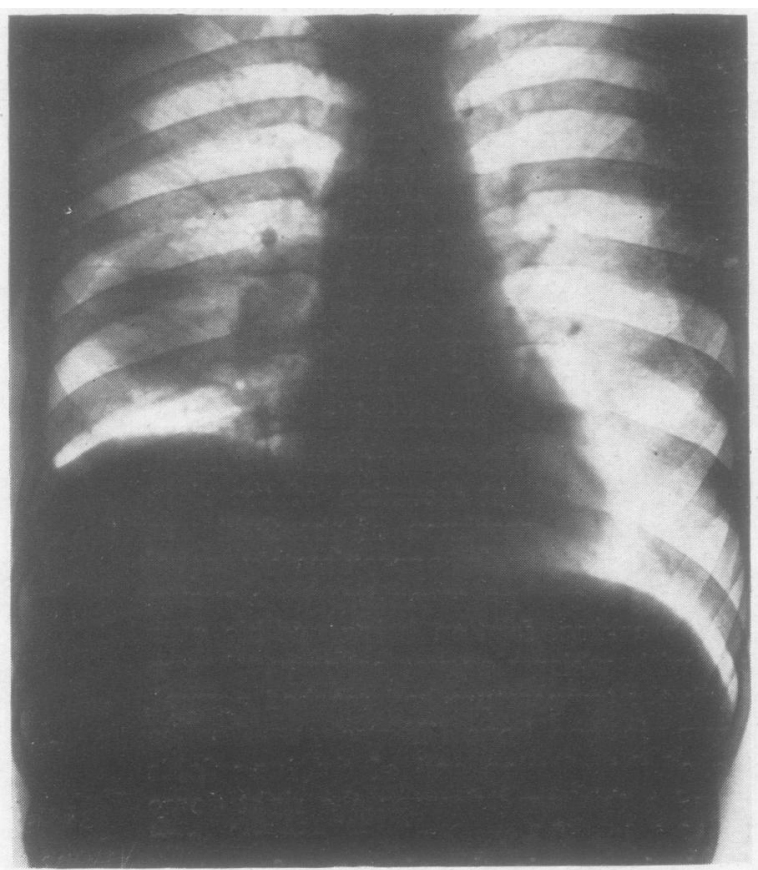

FIG. 6. - Case 2 fortieth day. Recrudescence of pneumonia; opacity in apical segment of right lower lobe.

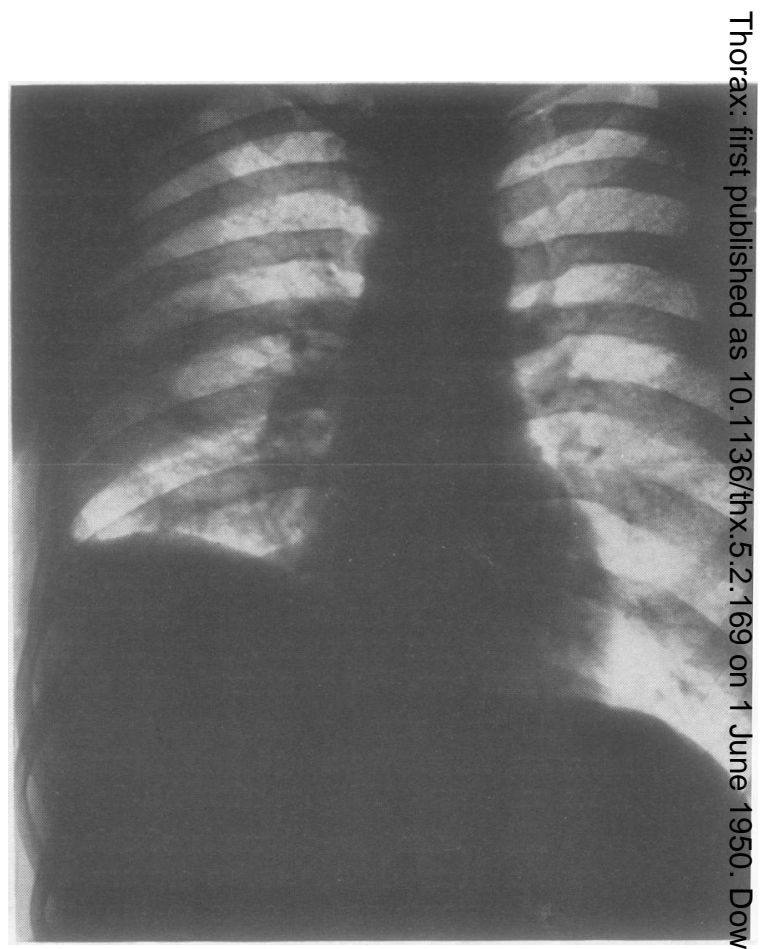

FIG. 5.-Case 2 twenty-eighth day. The right dome of the diaphragm is raised 2.1 in. $(5.3 \mathrm{~cm}$.) above its nornol 1 level. The effusion has absorbed.

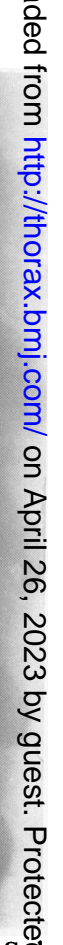

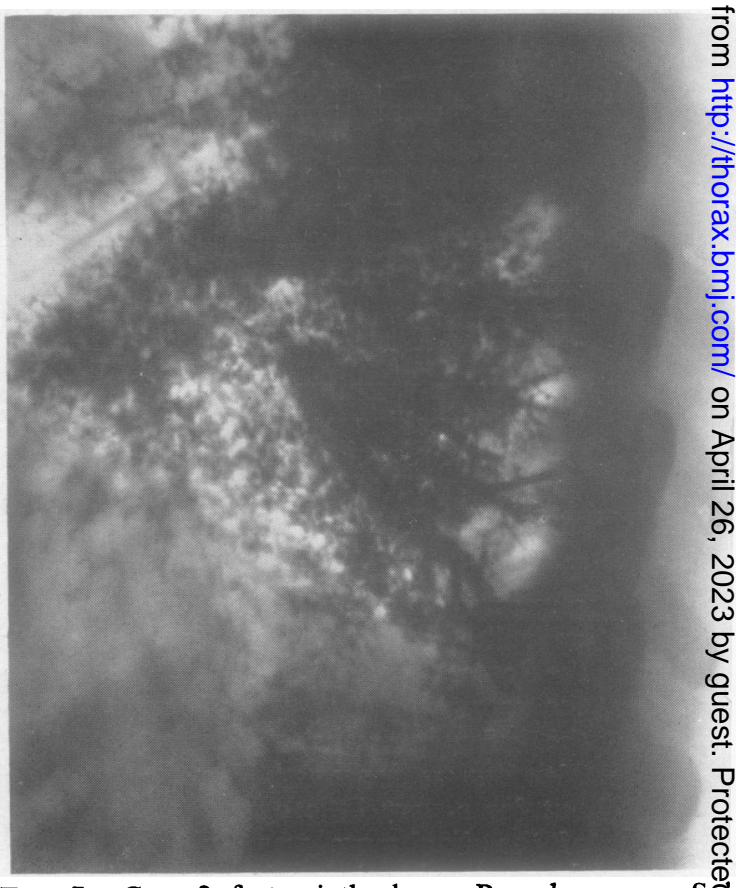

FIG. 7-Case 2 forty-ninth day. Bronchogram. S\&bpleural abscess cavity filled with oil communicates wh posterior basal branch of right lower lobe bronchus. 
yielded no tubercle bacilli. Leucocyte count was 18,000 per c.mm., with $81 \%$ polymorphs. The Mantoux test, 1:1,000, was positive.

On the 40th day radiography (Fig. 6) showed opacity of the apical segment of the right lower lobe. The diaphragmatic shadow; though still elevated on the right side, had now regained its clear. rounded contour. It exhibited paradoxical movement on fluoroscopy.

On the 49th day bronchography (Fig. 7) showed a small cavity at the right base posteriorly, level with the 11th interspace, situated within the chest wall, and communicating with the posteriorbasal branch of the lower lobe bronchus. This might have been a small empyema or a subpleural abscess originally, though at this stage no distinction was possible The apical segment of the lower lobe did not fill well, though the bronchus supplying it did so. Bronchoscopy showed no abnormality. No tubercle bacilli or malignant cells were found in the bronchial mucus, and no pathogenic organisms were grown from it.

On the 60th day there was evidence that the sepsis was subsiding. The leucocyte count was 10,000 per c.mm., with $78 \%$ polymorphs, and the E.S.R. 24 $\mathrm{mm}$. in 1 hour, and the temperature had been normal for 42 days, though moderate tachycardia persisted.

On the 73 rd day radiography showed moderate descent of the right dome from its elevated position, and the patient was therefore discharged. He failed to attend again until seven months later, when he was found to be in good health, free from

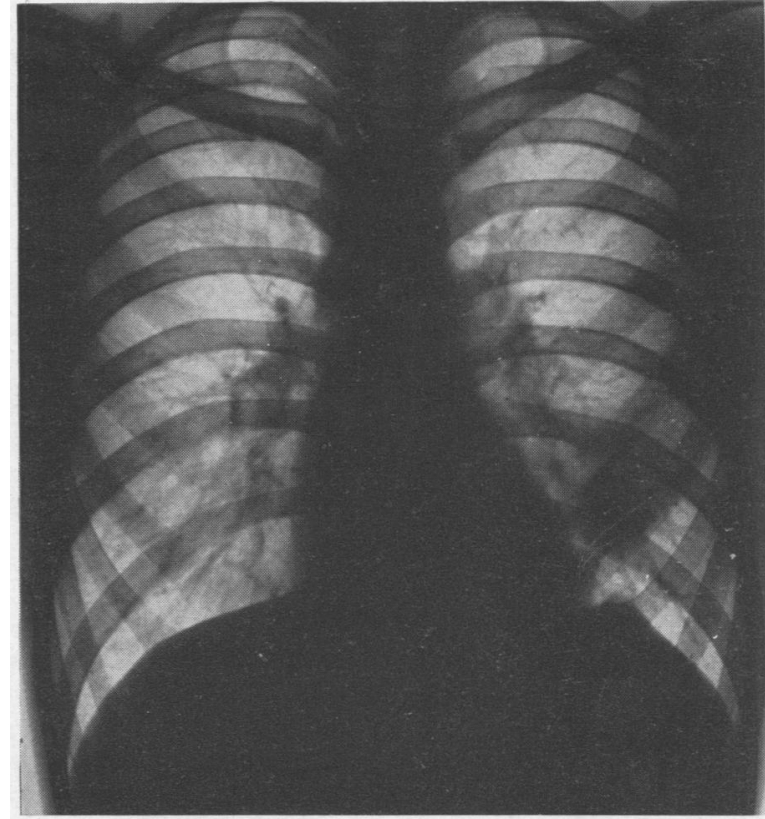

FIG. 8.-Case 3 thirty-sixth day after onset. Opacity slightly larger. Left dome of diaphragm peaked.

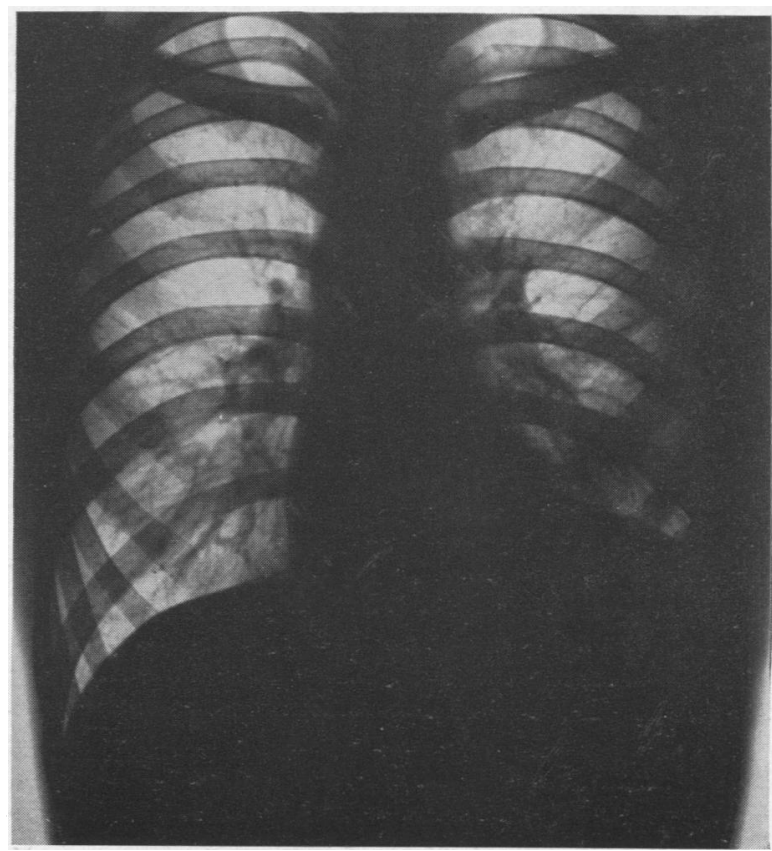

FIG. 9.-Case 3 sixty-third day. The left dome of the diaphragm is elevated $1.8 \mathrm{in} .(4.6 \mathrm{~cm}$.) above its normal level. The opacity in the lung field persists. 


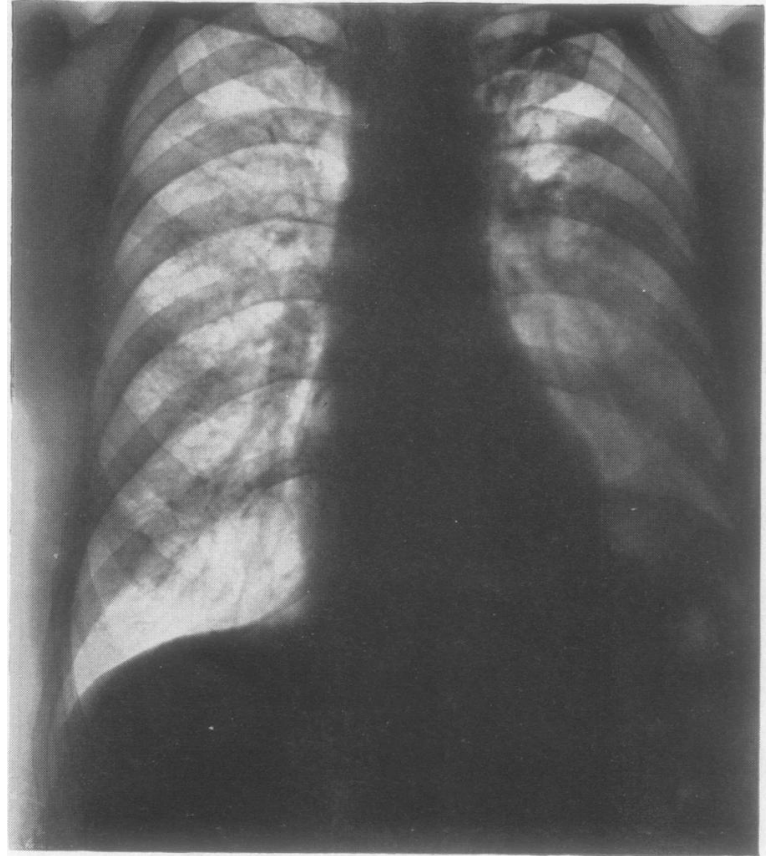

FIG. 10.

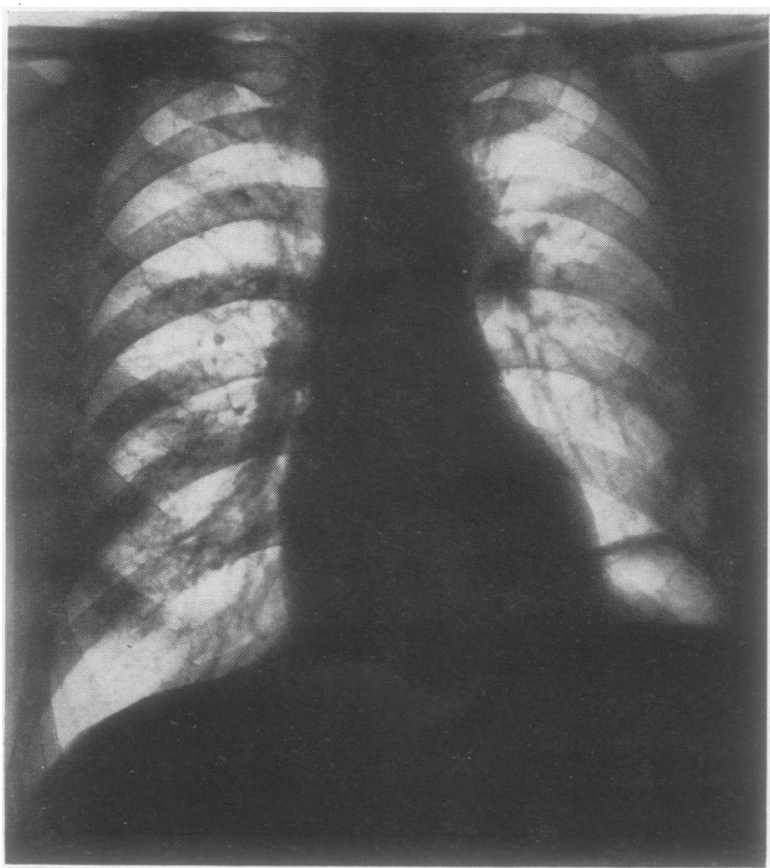

FIG. 11 symptoms, and to possess a normal chest on physical and radiological examination.

The diagnosis was pneumonia involving the base of the right lower lobe with formation of a subpleural abscess and a serous pleural effusion. There was a recrudescence of pneumonia in the apical segment of the right lower lobe on the 40th day. Paralysis of the right dome of the diaphragm was present on the 28th day of the illness, possibly beginning at the end of the first week. The duration of paralysis was uncertain, but probably a little over seven weeks.

Case 3.-An electrician's mate. aged 19 years, had had no relevant previous illness, but had felt out of sorts for three months, with irritability and slight loss of weight, when he developed slight cough, pain in the left side of the chest, and blood-stained sputum. He was admitted to hospital on the third day of illness (March 21, 1946). His temperature was $99.0^{\circ}$ F. $\left(37.2^{\circ}\right.$ C. $)$, pulse rate 80 , and respiration rate 22 . The patient was thin and sallow. but his general condition was good, and there were no abnormal physical signs in the chest or elsewhere. A radiograph showed

FIG. 10.-Case 4 third day of illness. Opacity due to pneumonia affecting the left lower lobe. The left dome of the diaphragm is raised 2.6 in. $(6.6 \mathrm{~cm}$.) above its normal level.

Fig. 11.-Case 4. Apparently permanent elevation of the affected dome. The pneumonia had resolved after three weeks. This radiograph was taken seven weeks after the onset, and is not essentially different from others taken during the next two years. 
an opacity, presumably pneumonic, in the left mid-zone. It was at no time of sufficient density to be visible in lateral views, and its exact location is therefore not known. The temperature was $99.6^{\circ} \mathrm{F}$. $\left(37.6^{\circ} \mathrm{C}\right.$.) on the fourth day, $103^{\circ} \mathrm{F}$. $\left(39.4^{\circ} \mathrm{C}\right.$. $)$ on the fifth, but thereafter it was normal. Pain persisted until the sixth day, by which time there was slight impairment of the percussion note, with diminution of breath sounds at the base of the left lung. No tubercle bacilli were seen in the sputum. Thereafter he made an uninterrupted recovery with clearing of the clinical signs, and was discharged on the 22nd day. As his disease was mild and progress appeared to be satisfactory, no specific treatment was given.

Two days after discharge the pain recurred, and the patient presented himself a fortnight later (36th day). His general condition was good; temperature, pulse and respiration rates normal; coarse friction was now present over the greater part of the left chest with some impairment of percussion note; there were no crepitations or rhonchi. The E.S.R. was $11 \mathrm{~mm}$. in one hour (Wintrobe); Mantoux test 1:1,000 positive. Radiography (Fig. 8) showed increase in the extent, though not in the density, of the opacity seen five weeks previously, and very slight elevation with peaking of the left dome of the diaphragm.

By the ninth week slight pain in the left chest was still occasionally present, but the general condition remained good with a pulse rate of 100 and temperature and respiration rate normal. Friction, though present, was much diminished, and there were impairment of percussion note and diminished breath sounds on the affected side. The E.S.R. was $22 \mathrm{~mm}$. in 1 hour. Radiography showed considerable elevation of the left dome of the diaphragm which was now $1.8 \mathrm{in}$. $(4.6 \mathrm{~cm}$.) above its normal level on inspiration, and on fluoroscopy exhibited paradoxical movement ; the shadow in the left mid-zone persisted unchanged (Fig. 9), but now appeared in the lower zone owing to ascent of the diaphragm. By the 10th week the diaphragm was still elevated and paralysed, and the opacity, now clearing, was gone a week later.

By the 16th week the position and movements of the diaphragm had returned to normal, the lung fields remained clear, and the peaking had gone. There were no symptoms or signs and the E.S.R. was $5 \mathrm{~mm}$. in one hour.

The illness was diagnosed as pneumonitis of the mid-zone of the left lung with dry pleurisy lasting 10 weeks. Paralysis of the left dome of the diaphragm was first detected at the fifth week and lasted for 11 weeks.

Case 4.-A woodworker, aged 63 years, had had pneumonia 25 years previously, and was subject to mild chronic bronchitis during the winter months. His illness started with a rigor, cough, pain in left side of the chest, and pink sputum. He was admitted to hospital on the second day (February 19, 1947). His general condition was good and there was no respiratory distress. Temperature $99.0^{\circ} \mathrm{F}$. $\left(37.2^{\circ} \mathrm{C}\right.$.), pulse rate 120 , respiration rate 24 per minute. Over the apical segment of the left lower lobe crepitations with tubular breathing and whispering pectoriloquy were present; over the rest of the lower lobe there were crepitations with impaired percussion note and diminished breath sounds. The leucocyte count was 22,000 per c.mm. with $98 \%$ neutrophils. He was treated with sulphadimidine (sulphamezathine) 1 g. 6-hourly for six days.

Radiography two days after the onset showed pneumonic opacity at the base of the left lung, with elevation of the left dome of the diaphragm to 2.6 in. $(6.6 \mathrm{~cm}$.) above normal (Fig. 10). The evening temperature remained at $99.0^{\circ} \mathrm{F}$. $\left(37.2^{\circ} \mathrm{C}\right.$.) for the first week, apart from an unexplained rise to $101.4^{\circ} \mathrm{F} .\left(38.6^{\circ} \mathrm{C}\right.$. $)$ on the sixth day; thereafter it remained normal.

At three weeks the patient was clinically well. Some diminution of the breath sounds at the left base was attributable to elevation of the diaphragm. 
Radiographs at intervals during the next two and a half years showed persistent elevation of the left dome of the diaphragm by 2.6 in. $(6.6 \mathrm{~cm}$.), with paradoxical movement (Fig. 11).

A bronchogram at the seventh week outlined a normal bronchial tree on the left side. In view of the persistent diaphragmatic paralysis bronchoscopy was performed six months after the onset, and this too was normal, except for a slight excess of mucus in the left main bronchus consistent with diminished expulsive power on that side.

The patient's general condition remains excellent and there is no sign of respiratory disability. A trace of iodized oil was still visible in the left lung field two years later.

The diagnosis was acute lobar pneumonia involving the left lower lobe, and paralysis of the left dome of diaphragm, probably occurring at the onset of acute illness, and apparently permanent.

Case 5.-A millwright's mate, aged 60 years, with no previous illness, had had pain in the left hypochondrium with dry cough for one month. The pain then became worse and he was admitted to hospital on July 28, 1947. The temperature was $101.4^{\circ} \mathrm{F}$. $\left(38.6^{\circ} \mathrm{C}.\right)$, pulse rate 84 , and respiration rate 128 per minute. The physical and radiological signs were those of a left-sided pleural effusion. Fourteen oz. (390 $\mathrm{ml}$.) of clear yellow fluid were aspirated from the second left interspace anteriorly.

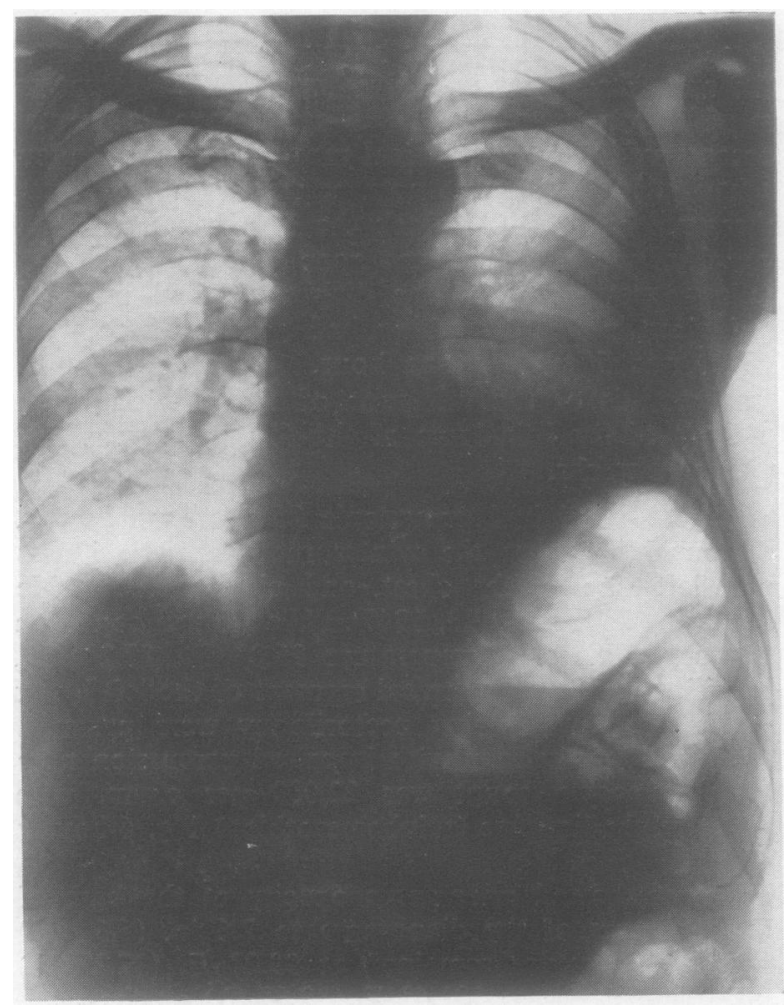

FIG. 12.-Case 5 fifteen days after admission to hospital with pleural effusion complicating pneumonia. The left dome of the diaphragm is raised $1.8 \mathrm{in} .(4.6 \mathrm{~cm}$.) above its normal level. very little being obtainable by posterior or lateral puncture. The fluid contained cells of which $40 \%$ were polymorphs and $60 \%$ lymphocytes; no organisms were grown and no tubercle bacilli were found in the deposit. One week later the polymorphs had increased to $70 \%$. The sputum grew a preponderance of pneumococcal colonies, and a few of Friedländer's bacillus ; no tubercle bacilli were found. The leucocyte count was 26,600 per c.mm. with $84 \%$ polymorphs. The patient was treated with sulphadiazine (1 g. 4-hourly) and penicillin $(30,000$ units 3-hourly) for nine days without response, the temperature gradually falling and reaching normal 26 days later.

Fifteen days after admission radiography (Fig. 12) showed a diminishing effusion, but elevation of the left dome of the diaphragm by 1.8 in. (4.6 $\mathrm{cm}$.). Fluoroscopy on the 19th day showed further elevation with paradoxical movement. Bronchoscopically the bronchial 
tree was normal. By the 30th day after admission the effusion had absorbed, and the patient was clinically well. As he was not under my immediate care, I did not see him again until five months later when clinically and radiologically the lungs were clear and diaphragmatic function normal.

In view of the patient's history on admission the onset of the illness may probably be taken at 28 days before that date. The leucocytosis favours a pyogenic infection and virtually excludes a primary tuberculous effusion. It is usual to find a fair proportion of lymphocytes in pneumonic effusions if the latter are non-purulent. It may be taken that his illness was a lobar pneumonia, of which the physical and radiological signs were masked by the presence of a sterile effusion. Paralysis of the left dome of the diaphragm occurred six weeks after the onset and persisted for an unknown period, but less than five months.

Case 6.-A housewife, aged 23 years, had suffered from recurrent bronchitis since 1942, and from cystitis in 1947. A primigravida, she was admitted to hospital on December 31, 1948, for delivery of twins. The progress of labour was slow, and owing to the death of one foetus she was delivered with forceps 44 hours after the beginning of labour. Premedication was atropine $1 / 100$ grain $(0.6 \mathrm{mg}$.) ; the anaesthetic was "kemithal," cyclopropane, and oxygen, and its administration lasted for 40 minutes. Bleeding from an upper vaginal tear was controlled with a pack. Apart from this delivery was straightforward. Morphine, $\frac{1}{4}$ grain $(15 \mathrm{mg}$.), was given postoperatively. There was no vomiting during or after anaesthesia. There were no symptoms or signs of respiratory or cardiac disease on admission.

On the day following delivery, the patient complained of pain in the right scapular region. Her temperature was $101.0^{\circ} \mathrm{F}$. $\left(38.3^{\circ} \mathrm{C}.\right)$, pulse rate 130 , respiration rate 40 per min., and there were signs of consolidation at the base of the right lung. She was given penicillin 60,000 units and sulphadimidine (sulphamezathine) $1 \mathrm{~g}$. 4hourly for five days. On the second day sonorous rhonchi were also present at the right base. The sputum was coloured a faint green.

On the fourth day breath sounds at the right base were much diminished, the percussion note was impaired, and rhonchi persisted. Radiography (Fig. 13) showed 1.8 in. (4.6 $\mathrm{cm}$.) elevation of the right dome of the diaphragm, but clear lung fields. There was some prominence of the conus. The temperature and the pulse and respiratory rates fell steadily, reaching normal on the fourth day, but a leucocytosis was still present (total 17,000 per c.mm. of which polymorphs were $70 \%$ ). No pneumonic shadow was seen in the postero-anterior radiograph; the situation of the physical signs suggested

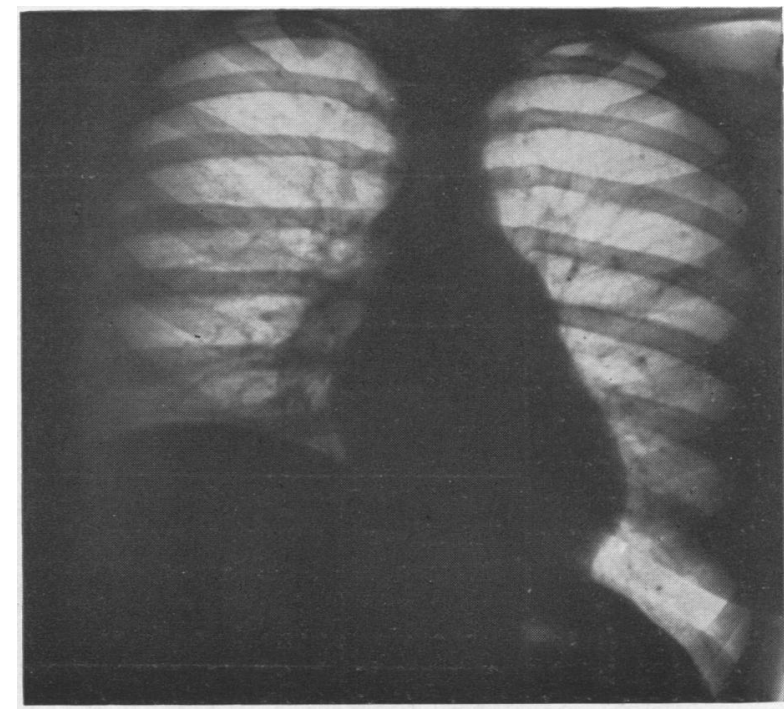

FIG. 13.-Case 6. Post-operative pneumonia on fourth day of illness. The right dome of the diaphragm is raised $1.8 \mathrm{in.}(4.6 \mathrm{~cm}$.) above its normal level. Lung fields appear clear in this view, as the affected tissue was situated behind the dome. 


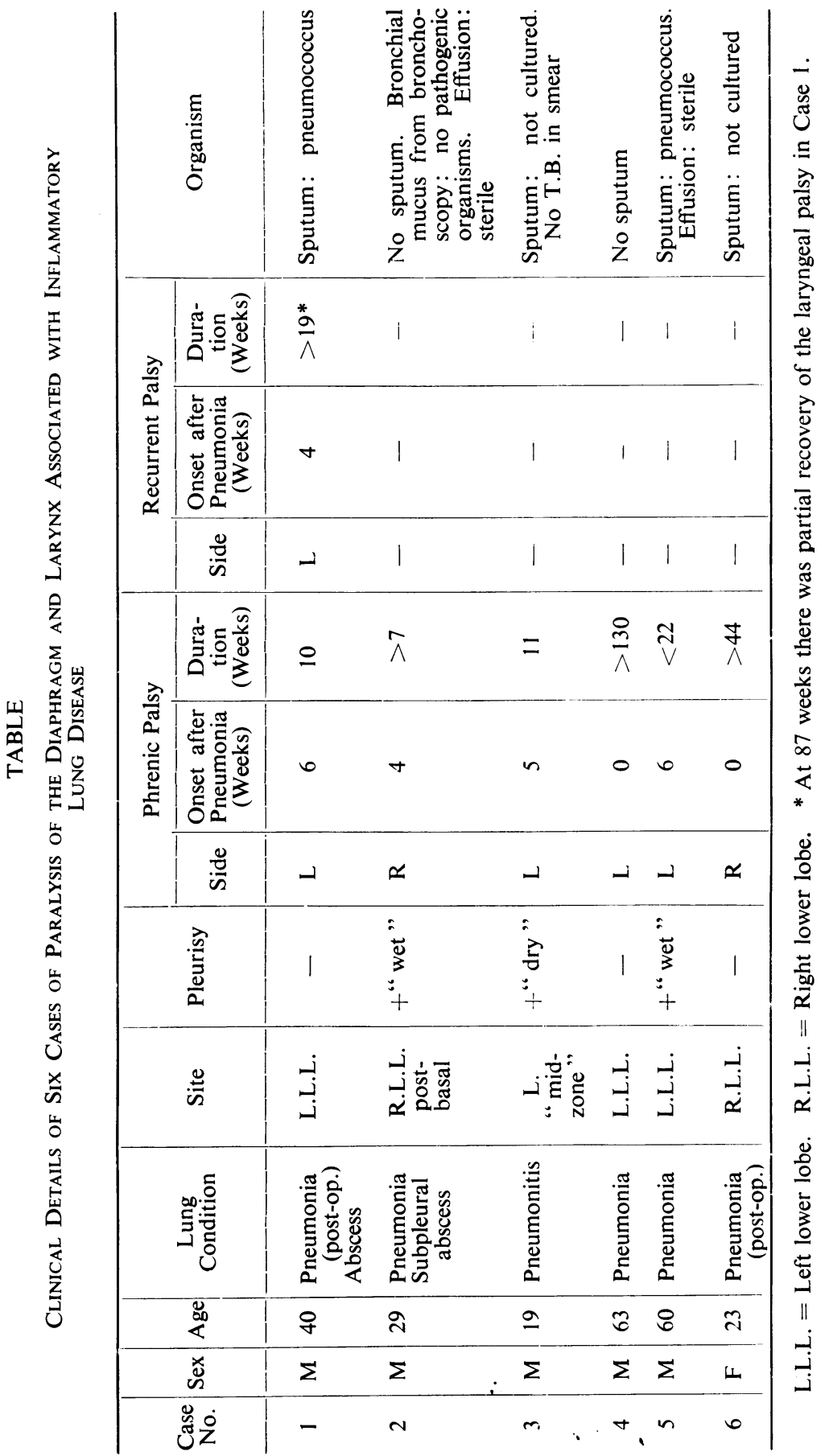


that the affected lung tissue lay in the lowest part of the posterior basal segment where it would be obscured by the shadow of the diaphragm.

Fluoroscopy confirmed elevation of the right diaphragm, which exhibited paradoxical movement. By the ninth day the affected dome was lower, but movement was still paradoxical, and it has remained so until the time of writing, 10 months later. There is very slight breathlessness on exertion, and moderate diminution of breath sounds at the right base; otherwise the patient remains well.

The diagnosis may be summed up as post-operative pneumonia affecting the right lower lobe, with paralysis of the right dome of the diaphragm beginning at the onset of the pneumonia, or shortly after, and improving after one week, but with weakness still present 10 months later

\section{Discussion}

The tabulated findings reveal certain features in common as well as certain features of difference between the cases. A lower lobe was concerned in five of the six cases. Pleurisy was present in three cases, two of which were accompanied by effusion, the third being "dry." In two of the six cases diaphragmatic paralysis probably occurred at the onset of the acute illness. In the four other cases the paralysis occurred on an average five-and-a-quarter weeks after the onset of the acute illness. There was a similar latent period in the onset of the vocal cord paralysis in Case 1, namely four weeks. The duration of the diaphragmatic paralysis is known for certain in only two cases, 10 and 11 weeks respectively. In a third (Case 2) it was probably a little over seven weeks. In another two cases it is still present after 44 and 130 weeks. Owing to follow-up difficulties the duration in the remaining case is not certainly known, but it was less than 22 weeks.

Pneumococci were grown from the sputum of two cases. No sputum was produced by two others, and none was sent for culture from the remaining two. The pleural effusions were sterile.

Two cases were post-operative, and two were associated with lung abscess.

There seem to be two possible ways in which pneumonia may bring about paralysis of the diaphragm and, on occasion, the ipsilateral vocal cord (left). One is a toxic or inflammatory neuritis of the phrenic and recurrent laryngeal nerves. The other is a toxic or inflammatory diaphragmitis. The evidence in support of the latter explanation is not strong. Long-standing empyemata may cause degeneration of the fibres of the diaphragm. Waxy degeneration is sometimes seen in fatal cases of pneumonia and anaphylaxis ; it is due to overwork of the diaphragm or to asphyxia (Wells, 1927). In none of these conditions is there evidence that the diaphragm is paralysed. Norris and Landis (1938) state that pleural effusion may cause "crippling of the function of the diaphragm . . . if the effusion has been present some time" ; these authors make no mention of paralysis. Only two of the six cases described had pleural effusion, and one had dry pleurisy. The following facts are against this explanation in the cases described. It does not account for the four cases without effusion, nor for the laryngeal palsy. The effusions were not purulent, and grew no organisms; a toxic or bacterial diaphragmitis therefore seems unlikely. In my opinion a toxic or inflammatory neuritis of the phrenic and left recurrent laryngeal nerves was the operative factor, for this would fully explain the clinical phenomena. Whenever a motor nerve is situated in a toxic medium, loss of function may occur, and the longer the nerve the greater is the length exposed to noxious influences. 
The vulnerability of the cranial nerves, especially the sixth, in meningitis is an example.

The phrenic nerves take a long course through the thorax and throughout that course they are situated immediately under the mediastinal pleura, where they are liable to damage by toxins present in the pleural cavity. There is also a possibility that, where the nerves pass in front of the respective lung hila, they would be exposed to toxins travelling in the bronchial lymphatics.

The left recurrent laryngeal nerve fibres before they leave the vagus trunk are likewise situated subpleurally. Their shorter subpleural course corresponds to the lower incidence of paralysis ( 1 in 6).

Unilateral diaphragmatic paralysis in itself causes very little disability. There would appear to be no practicable form of treatment for the one patient with apparently permanent paralysis, nor is it necessary, since he is not conscious of any disability.

These six cases were encountered in the medical wards of a general hospital in the course of three years. It is surprising therefore that no previous record of this condition exists in the literature. I believe that the condition may be relatively common, but that it has hitherto escaped notice, first because the onset of the paralysis is delayed until after the patient has been discharged from hospital, and secondly because the paralysis itself gives rise to no symptoms that would cause the patient to return for medical advice.

\section{SUMMARY}

Six cases of unilateral paralysis of the diaphragm in association with pneumonia are described. The paralyses occurred on the same side as the pneumonia.

In one of these there was also ipsilateral vocal cord paralysis.

The onset of paralysis was probably coincidental with that of the pneumonia, or only slightly delayed in two cases ; in the remaining four there was a latent interval of over five weeks. The paralysis lasted many weeks, and in one case is probably permanent.

Two cases were associated with pleural effusion, one with dry pleurisy, and two with lung abscess. Two were post-operative.

Reasons are given for the opinion that the paralyses were the result of toxic or inflammatory neuritis involving the phrenic nerves and the left recurrent laryngeal nerve.

\section{REFERENCES}

Blattner, R. J. (1942). J. Pediat., 20, 225.

Davies, D. T., Hodgson, H. G., and Whitby, L. E. H. (1935). Lancet, 1, 919.

Graeser, J. B., Wu, C., and Robertson, O. H. (1934). Arch. intern. Med., 53, 249.

Heffron, R. (1939). Pneumonia. The Commonwealth Fund, New York; Oxford University Press.

Kienböck, R. (1898). Wien. klin. Wschr., 11, 538 and 1178.

Leitner, St. J. (1938). Schweiz. med. Wschr., 19, 747.

Light, J. S. (1944). J. Pediat., 24, 627 (Case 1).

Norris, G. W., and Landis, H. R. M. (1938). Diseases of the Chest, p. 781. Saunders, Philadelphia .

Sanguinetti, A. A., and Galzerano, D. A. (1943). Rev. Asoc. méd. argent., $57,413$.

Stivelman, B. P. (1935). Amer. J. med. Sci., 190, 256.

Udaondo, C. B., and Vadone, A. (1929). Amer. Rev. Tuberc., 20, 741.

Wells, H. G. (1927). Arch. Path. Lab. Med., 4, 681.

Wu, C. (1932). Radiology, 19, 215. 